\title{
Large mode area double clad ytterbium tapered fiber with circular birefringency
}

\section{Citation}

Rissanen, J., Fedotov, A., Noronen, T., Gumenyuk, R., Chamorovskii, Y., Kolosovskii, A., ... Filippov, V. (2019). Large mode area double clad ytterbium tapered fiber with circular birefringency. In A. L. Carter, \& L. Dong

(Eds.), Proceedings of SPIE : Fiber Lasers XVI: Technology and Systems (Vol. 10897). (Proceedings of SPIE; Vol. 10897). SPIE-INT SOC OPTICAL ENGINEERING. DOI: 10.1117/12.2508811

Year

2019

\section{Version}

Publisher's PDF (version of record)

\section{Link to publication}

TUTCRIS Portal (http://www.tut.fi/tutcris)

\section{Published in}

Proceedings of SPIE

\section{DOI}

10.1117/12.2508811

\section{Copyright}

Copyright 2019 Society of Photo-Optical Instrumentation Engineers (SPIE). One print or electronic copy may be made for personal use only. Systematic reproduction and distribution, duplication of any material in this paper for a fee or for commercial purposes, or modification of the content of the paper are prohibited.

\section{Take down policy}

If you believe that this document breaches copyright, please contact tutcris@tut.fi, and we will remove access to the work immediately and investigate your claim. 


\section{Large mode area double clad ytterbium tapered fiber with circular birefringency}

Joona Rissanen, Andrei Fedotov, Teppo Noronen, Regina Gumenyuk, Yuri Chamorovskii, et al.

Joona Rissanen, Andrei Fedotov, Teppo Noronen, Regina Gumenyuk, Yuri Chamorovskii, Alexander Kolosovskii, Victor Voloshin, Igor Vorobev, Maxim Odnoblyudov, Valery Filippov, "Large mode area double clad ytterbium tapered fiber with circular birefringency," Proc. SPIE 10897, Fiber Lasers XVI: Technology and Systems, 1089725 (7 March 2019); doi: 10.1117/12.2508811

SPIE. Event: SPIE LASE, 2019, San Francisco, California, United States 


\title{
Large mode area double clad ytterbium-doped tapered fiber with circular birefringence
}

\author{
Joona Rissanen ${ }^{\mathrm{a}, \mathrm{b}^{*}}$, Andrei Fedotov ${ }^{\mathrm{b},{ }^{*}}$, Teppo Noronen $^{\mathrm{a}}$, Regina Gumenyuk ${ }^{\mathrm{a}, \mathrm{b}}$, Yuri Chamorovskiy ${ }^{\mathrm{c}}$, \\ Alexander Kolosovskii ${ }^{\mathrm{c}}$, Victor Voloshin ${ }^{\mathrm{c}}$, Igor Vorobev ${ }^{\mathrm{c}}$, Maxim Odnoblyudov and Valery \\ Filippov $^{\mathrm{a}}$ \\ ${ }^{a}$ Ampliconyx Ltd, Lautakatonkatu 18, 33580 Tampere, Finland; ' Tampere University, Kalevantie 4, \\ 33100 Tampere, Finland; 'Kotel'nikov Institute of Radio Engineering and Electronics, Mokhovaya \\ 11, bld.7, 125009 Moscow, Russian Federation \\ *authors equally contributed to the work \\ E-mail: valery@ampliconyx.com
}

\begin{abstract}
We demonstrated, for the first time to our best knowledge, an active tapered double clad fiber with circular birefringence and $35 \mu \mathrm{m}$ core diameter. The output radiation had perfect beam quality $\left(\mathrm{M}^{2}=1.18 / 1.1\right)$ and linearly polarized light with $15 \mathrm{~dB}$ of PER. The developed double clad active fiber was investigated for amplification of picosecond pulses in allfiber MOPA system. The MOPA system delivered 50 ps pulses with $55 \mathrm{~W}$ of the average power revealed $34.4 \mathrm{~dB}$ gain of the booster amplifier.
\end{abstract}

Keywords: fiber laser, active spun fiber, active tapered fiber, ultrafast fiber amplifier

\section{INTRODUCTION}

Technology of active double clad fibers (T-DCF) has been developing rapidly during last decade ${ }^{1,2}$. Similar to low numerical aperture large mode area fiber (NA LMA), large pitch fiber (LPF) and 3C fibers, active T-DCF represents LMA fibers with relatively high NA and a record-breaking core size (up to $100 \mu \mathrm{m}$ ), at the same time maintaining a single-mode propagation regime. The large core size significantly increases the threshold of nonlinear effects and allows to extract high peak/average power. Numerous active fiber-optic devices comprising T-DCF have been already demonstrated: $\mathrm{kW}$-class $\mathrm{CW}$ single mode fiber lasers ${ }^{3,4}$, high gain and high-power $\mathrm{CW}$ amplifiers ${ }^{5}$, ultrafast picosecond amplifiers $^{6,7}$, high power superfluorescent sources ${ }^{1}$ and narrow band fiber amplifiers and lasers ${ }^{8}$.

The early works implemented the capabilities of the T-DCFs technology by utilizing the fibers without internal birefringence ${ }^{1,3,4,5}$. Recently, the family of scientific works has increased by experimental demonstration of the passive and active anisotropic tapers with an elliptical core of $70 \mu \mathrm{m}$ size $^{9}$ and stress rods (PANDA type) $)^{7,8}$. To date, the PANDA type of the active T-DCF are the most common to maintain the polarization of the linearly polarized light. However, despite of the fact that the technology of PANDA type fibers is well-developed and widely-used, complexity of the preform manufacturing process and strong mechanical stresses still remain the serious drawbacks of the method. Especially, it becomes more important for the large core area of T-DCFs.

The PANDA type fiber is not a unique approach to create birefringence in the fiber. By twisting preform during a fiber drawing process, it is possible to form the stresses, which support a propagation of polarized light. The fibers fabricated by this method are so-call spun fibers ${ }^{10}$. The spun fibers are extensively utilized for sensing applications ${ }^{11}$. They have an internal circular birefringence, and they are not sensitive to the orientation of launched linearly polarized light. The spun fibers approach is less time-consuming, simpler and cheaper. Therefore, they are good alternative technology for polarization-maintaining high-power fiber amplifiers.

In the present work, we, for the first time to our best knowledge, experimentally demonstrated the active ytterbium doped tapered fiber with internal circular birefringence (spun T-DCF, or sT-DCF). We exploited the fabrication method for the large core active fibers and investigated their polarization and amplification properties. The all-fiber picosecond MOPA system based on the Yb-doped spun tapered fiber was successfully realized for the first time.

Fiber Lasers XVI: Technology and Systems, edited by Adrian L. Carter, Proc. of SPIE Vol. 10897, $1089725 \cdot$ (c) 2019 SPIE · CCC code: $0277-786$ X/19/\$18 · doi: 10.1117/12.2508811 


\section{SPUN TAPERED Yb-DOPED DOUBLE CLAD FIBER}

\subsection{Basic optical properties of sT-DCF}

For manufacturing of sT-DCF we used a step-index Yb-doped preform, which index profile is shown in Figure 1a. The in-core absorption value was equal to $650 \mathrm{~dB} / \mathrm{m}$ at $976 \mathrm{~nm}$, and the numerical aperture was 0.1 . The preform was assembled with core-cladding-diameter ratio (CCDR) equaled to 8. The sT-DCF was drawn by utilizing the similar technology used previously for a passive spun type fiber ${ }^{12}$. The fiber drawing process was performed by continuous variation of the drawing speed to obtain the fiber tapering, at the same time the preform was rotated with the constant velocity. The fiber was tapered dawn from $800 \mu \mathrm{m}$ to $125 \mu \mathrm{m}$ of outer cladding diameter along the length of $5 \mathrm{~m}$. The profile of sT-DCF is shown in Figure 1b. In order to improve the double clad absorption, the preform was truncated four times. The end face image of the sT-DCF fiber obtained from the wide side is depicted in Figure 1b (inset). The clad absorption in the sT-DCF was $12 \mathrm{~dB}$ for $976 \mathrm{~nm}$ pump wavelength.

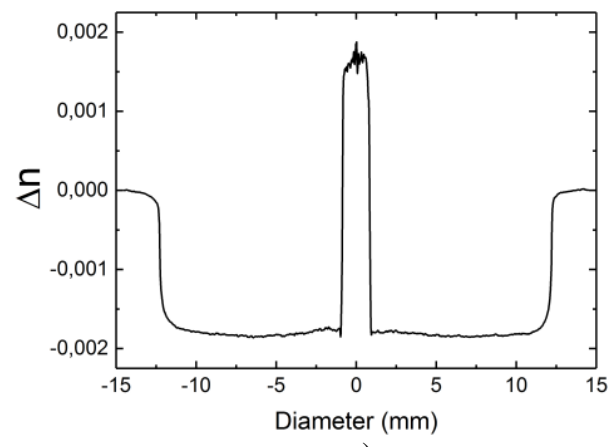

a)

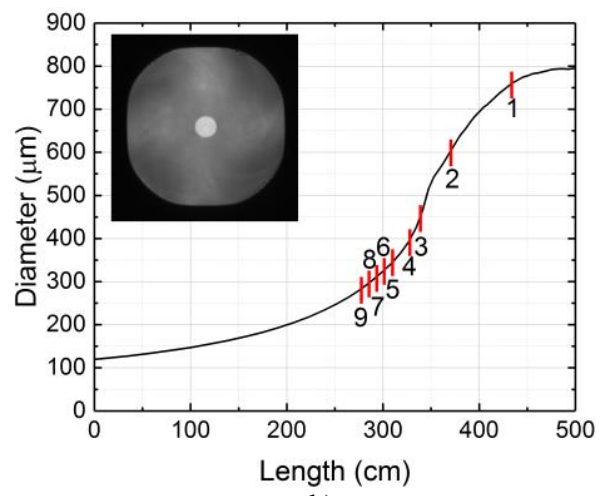

b)

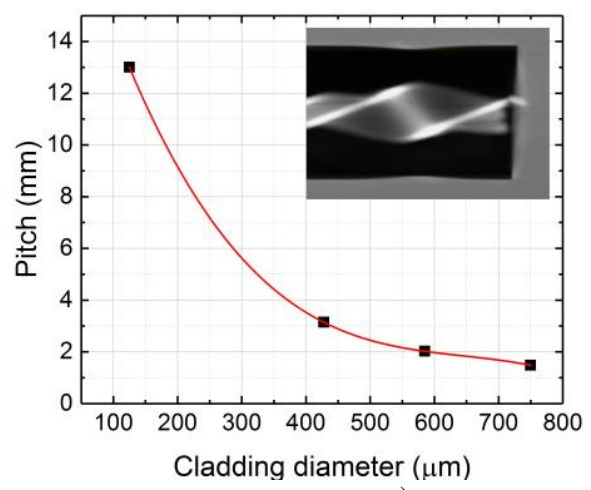

c)

Fig. 1. a) Refractive index profile of the preform; b) The variation of outer cladding diameter with the sT-DCF length. Inset: end face image of the drawn fiber; c) The pitch as a function of the cladding diameter. Inset: the side view of the spun taper.

Since the drawing speed of the taper varied during the process, the pitch changed along the length of the sT-DCF simultaneously with tapering of the fiber diameter. The measured dependence of the pitch versus the clad diameter of the tapered fiber is presented in Figure 1c. The pitch of sT-DCF increased from $2 \mathrm{~mm}$ at the widest side part till $13 \mathrm{~mm}$ at thinnest fiber diameter. Figure 1c (inset) demonstrates the side view of the spun fiber at the wide part with the pitch equaled to $2 \mathrm{~mm}$. The variation of the pitch along the sT-DCF length also led to the change of the local birefringence.

\subsection{Output beam profile parameters}

In the experiment, we investigated the dependence of the output beam shape on the core diameter of sT-DCF. For this, we sequentially shortened the taper from the initially drawn core/cladding diameter of 100/800 $\mu \mathrm{m}$ down to $35 / 280 \mu \mathrm{m}$, and measured the mode field distribution and $\mathrm{M}^{2}$-parameter of the output beam. The results are summarized in Table 1. 
Table 1. Output beam shape and $\mathrm{M}^{2}$-parameter of the beam quality as a function of the core/cladding diameter.

\begin{tabular}{|c|c|c|c|}
\hline Length, cm & 430 & 370 & 340 \\
\hline Core/cladding, $\mu \mathrm{m}$ & $95 / 760$ & $75 / 600$ & $56 / 450$ \\
\hline $\mathrm{M}^{2}$-parameter & 一 & - & - \\
\hline \multicolumn{4}{|l|}{ Near field beam shape } \\
\hline Length, cm & 330 & 310 & 300 \\
\hline Core/cladding, $\mu \mathrm{m}$ & $50 / 400$ & $42 / 340$ & $41 / 325$ \\
\hline $\mathrm{M}^{2}$-parameter & 一 & $1.93 / 2.02$ & $1.84 / 2.13$ \\
\hline \multicolumn{4}{|l|}{ Near field beam shape } \\
\hline Length, cm & 290 & 280 & 275 \\
\hline Core/cladding, $\mu \mathrm{m}$ & $39 / 310$ & $36 / 287$ & $35 / 280$ \\
\hline $\mathrm{M}^{2}$-parameter & $1.85 / 1.88$ & $1.21 / 1.33$ & $1.18 / 1.10$ \\
\hline Near field beam shape & & & \\
\hline
\end{tabular}

The output beam was strongly distorted due to the torsional mechanical stresses when the core/cladding diameter exceeded 56/450 $\mu \mathrm{m}$ (Table 1). With decreasing of the core/cladding diameter down to 50/400 $\mu \mathrm{m}$, the beam became single-mode, but moon-shaped, and it was pushed off the core centre towards to the side. Each further step of the fiber reduction led to the improvement in the beam shape and $\mathbf{M}^{2}$-parameter. Finally, the beam became round-shaped and filled the most area of the fiber core when the core/cladding diameter reached value of 35/280 $\mu \mathrm{m}$, (Table 1). These core/cladding dimensions corresponded to $6 \mathrm{~mm}$ of the pitch as seen from Figure 1c. At these parameters, the output of sT-DCF in amplification regime had a near diffracted limited pure fundamental mode with $\mathrm{M}^{2}{ }_{\mathrm{x}}=1.18$ and $\mathrm{M}_{\mathrm{y}}^{2}=1.10$ (Fig. 2a).

In order to measure the physical size of the beam, we took two shots using CCD beam profiler. The first one was the image of the end face of the fiber without pumping, so that the core was visible and measurable. The second one depicted the output beam in the amplification regime and its profile. After that, we compared these two pictures side by side and estimated a mode field diameter at the level of $13.5 \%$. Following this technique, we obtained the mode field diameter equaled to $26 \mu \mathrm{m}$ for the sT-DCF with 35/280 $\mu \mathrm{m}$ cladding (Fig. $2 \mathrm{~b}$ ). Thus, the MFD occupied $75 \%$ of the core. 


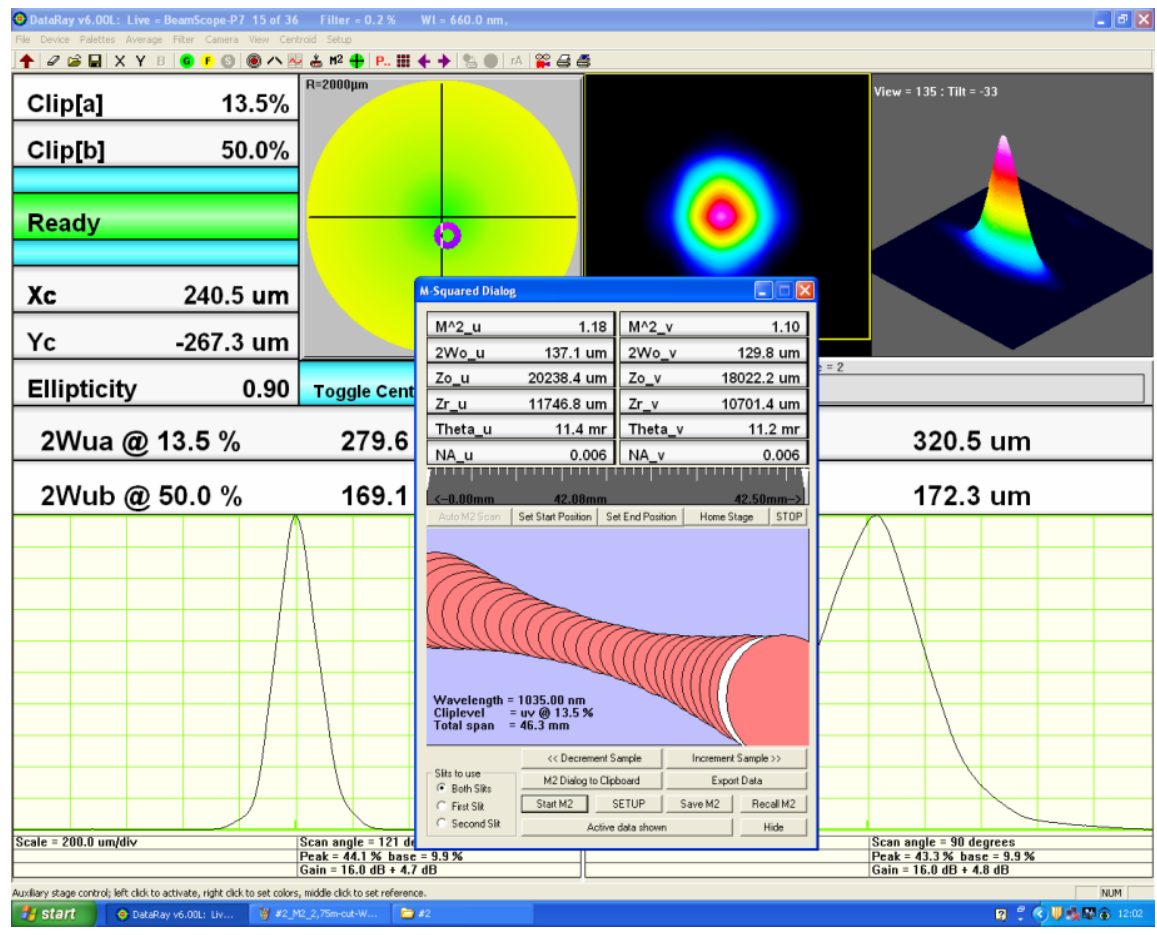

a)

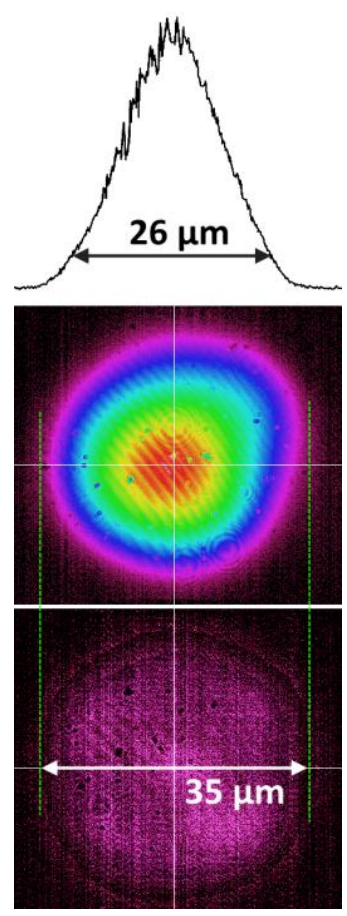

b)

Fig. 2. a) $\mathrm{M}^{2}$ measurement for sT-DCF with $35 / 280 \mu \mathrm{m}$ core/cladding dimensions; and b) its core and beam size at the level of $13.5 \%$.

\section{PICOSECOND MOPA WITH ST-DCF}

To investigate the sT-DCF polarization and amplification properties, we built an experimental setup of all-fiber MOPA system shown in Fig. 3. The co-propagating pump and signal were launched into the narrow side of sT-DCF via the pump combiner. A high-power isolator was used to protect the seed laser from back reflections that could cause a damage or introduce instabilities. The counter-propagating pump was injected through the dichroic filter and focusing lens. We used $27 \mathrm{~W}$ and $80 \mathrm{~W}$ wavelength stabilized laser diodes for pumping from narrow and wide sides. The active spun tapered fiber was wound with a diameter of $35 \mathrm{~cm}$ and set in the metal grooves with water-cooling.

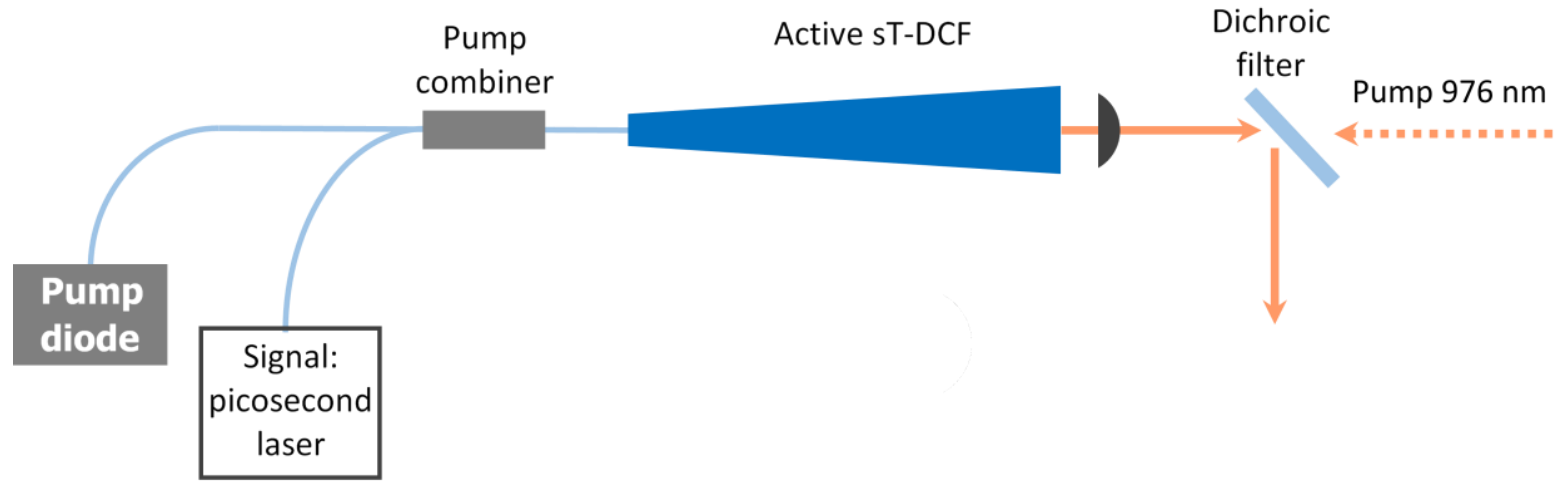

Fig. 4. The experimental setup of all-fiber MOPA system with sT-DCF. 


\subsection{Polarization properties}

The polarization properties of the sT-DCF in amplification regime was examined by using a commercial PM pigtailed gain-switched diode from PicoQuant $\mathrm{GmbH}$. The PM laser diode were characterized by a central wavelength of $1064 \mathrm{~nm}$ and a spectrum width (FWHM) of $40 \mathrm{pm}$ (Fig. 4). The repetition rate of the seed source could be tuned from $1 \mathrm{MHz}$ to $80 \mathrm{MHz}$. For our experiments, we used the repetition rate of $80 \mathrm{MHz}$, because it provided the highest output power of the signal (approximately $2 \mathrm{~mW}$ ). Higher repetition rate was also beneficial to minimize amplified spontaneous emission, which could deteriorate the results of PER measurements. The pulse duration was equal to $80 \mathrm{ps}$. The polarization extinction ratio of the signal launched into a sT-DCF was measured as high as $15 \mathrm{~dB}$.

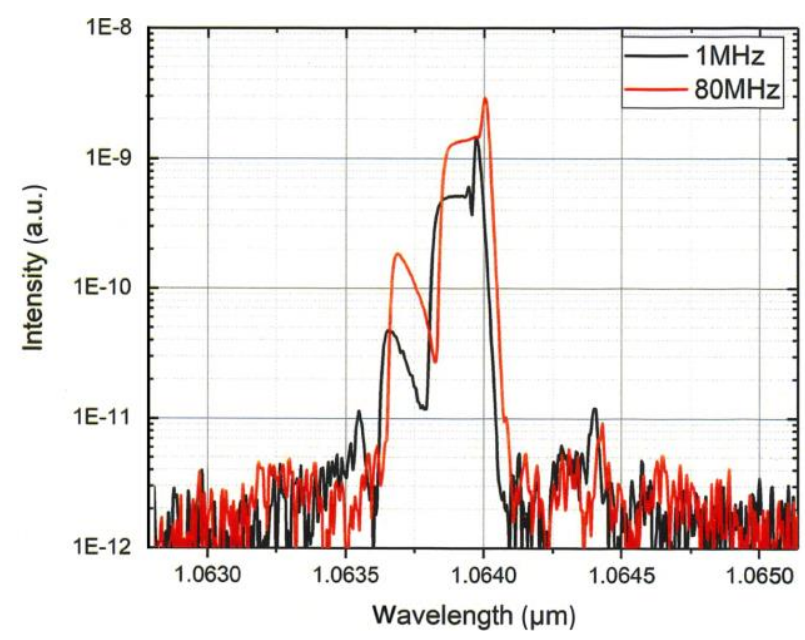

Fig. 4. The spectrum of the $1064 \mathrm{~nm}$ seed laser at repetition rates of $1 \mathrm{MHz}$ and $80 \mathrm{MHz}$.

The spatial uniformity of polarization and polarization extinction ratio of the output beam in amplification regime were studied in the following experiment. For a qualitative assessment of the spatial uniformity of the amplified radiation, we set a Glan-Taylor polarizer in front of the beam profiler and took a series of shots at different azimuth of polarizer. Figure 5a shows the intensity distribution of the output beam in the near field zone after passing through the polarizer for four different orientations of the polarizer (at $0,30,60$, and 90 degrees). The upper row series belongs to sT-DCF length of $340 \mathrm{~cm}$; the bottom series belongs to tapered fiber length of $275 \mathrm{~cm}$.

In both cases, the beam intensity decreased uniformly with rotation of the polarizer, which indicated that the beams were single-mode and polarization was uniform across the core. This confirmed our assumption that, although strong internal stresses distorted and displaced the beam relatively the core center, it retained the launched single-mode properties until the core diameter reaches $56 \mu \mathrm{m}$.
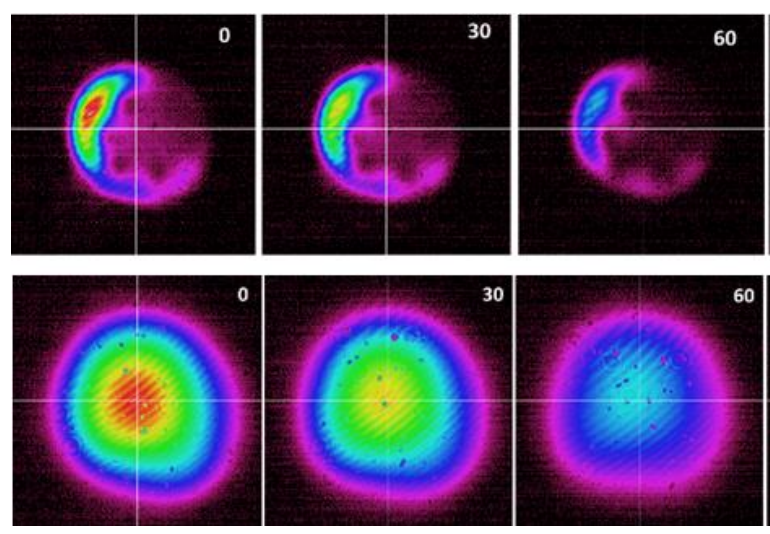

a)
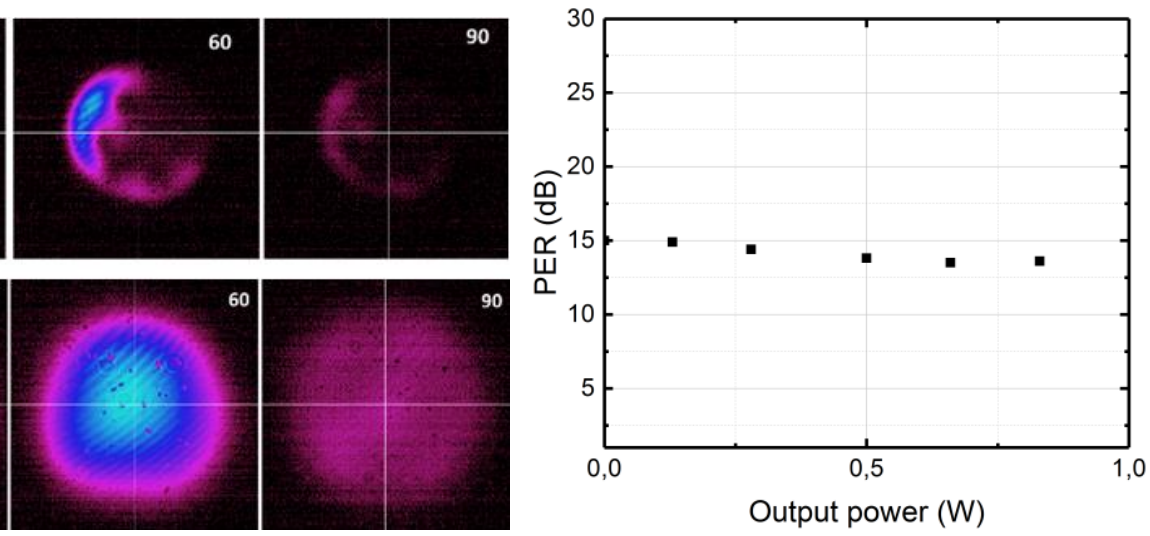

b)

Fig. 5. a) The beam shape versus azimuth of polarizer, b) Polarization extinction ratio versus output power. 
The polarization extinction ratio of the output beam was measured using Glan-Taylor polarizer and power meter. We placed the power meter after the polarizer and measure the output power for two cases: 1) when azimuth of polarizer coincided with polarization vector of the beam, and 2) when angle between them was equal to 90 degrees. Then PER parameter was calculated by the formula $\mathrm{PER}=10 \lg \left(\mathrm{P}_{1} / \mathrm{P}_{2}\right)$. We also investigated the dependence of the output power on the PER value. The data were presented for the output power within the range from 0 to $0.83 \mathrm{~W}$ determined by the power meter limit (Fig. 5b). The sT-DCF output was linearly polarized with PER ranging from 14 to $15 \mathrm{~dB}$ at the constant value of PER for the input signal equaled to $15 \mathrm{~dB}$. The state of polarization remained linear, although the extinction decreased slightly with increasing of the output power (Fig. 5b). In this experiment, we were also limited in terms of the output power because of low input power of the PM seed laser. A further increase of the pump power led to a growth of spontaneous emission, and as a result, a degradation of PER, since spontaneous emission always exhibited non-polarized property.

\subsection{Amplification properties}

The amplification properties of sT-DCF were investigated by utilizing another fiber-based seed laser. Mode-loked laser delivered $4.2 \mathrm{~nm}$ spectrum width at the central wavelength of $1035 \mathrm{~nm}$. The laser emitted $50 \mathrm{ps}$ pulses with repetition rate of $14.8 \mathrm{MHz}$. This seed laser was favorable for testing of the sT-DCF amplification properties due to higher output power $(20 \mathrm{~mW})$ and broader spectrum, which allowed extracting of more energy from the amplifier.

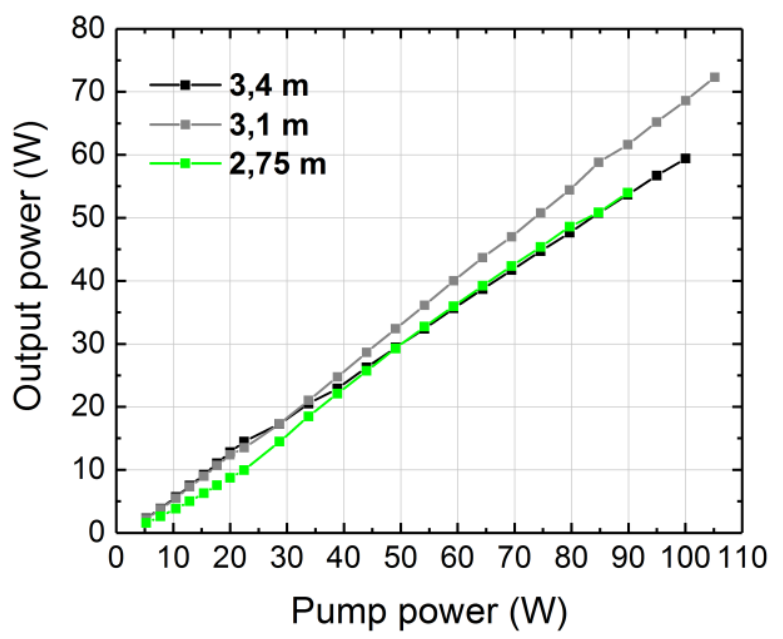

a)

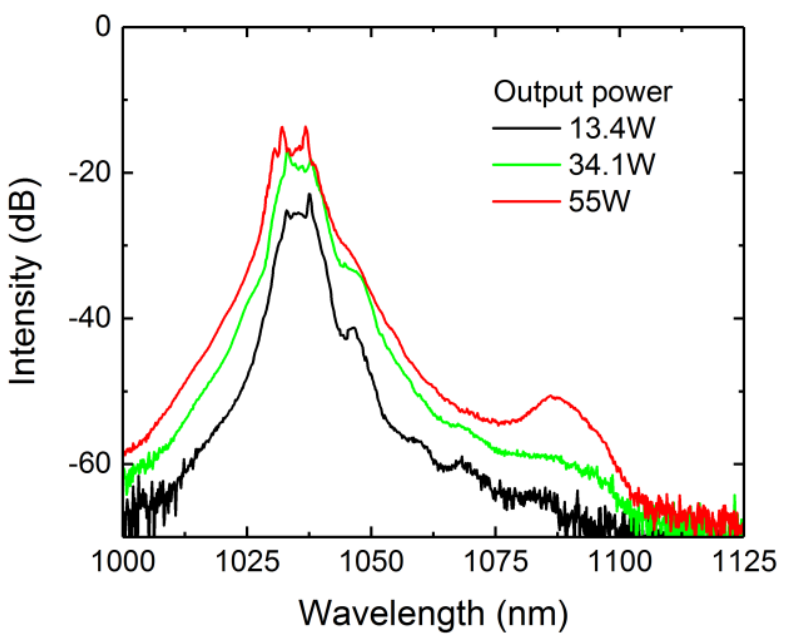

b)

Fig. 6. a) signal output power versus pump power (in comparison of different sT-DCF's lengths), and b) spectra of the output signal at different output power levels.

We measured the amplification properties for fiber samples with three lengths: $3.4 \mathrm{~m}, 3.1 \mathrm{~m}, 2.75 \mathrm{~m}$ (Fig. 6a). Since the earlier results revealed the good quality of the beam for the maximum length equaled to $2.75 \mathrm{~m}$, we provided the detail description only for the experiment with this particular sample.

At the first stage, the sT-DCF was pumped only through the narrow side via pump combiner by wavelength-stabilized diode operated at $976 \mathrm{~nm}$. We launched $22 \mathrm{~W}$ pump power from the narrow side and reached $10 \mathrm{~W}$ of the output power with slope efficiency equaled to $45 \%$ (Fig. 6a, green line). At the second stage, the sT-DCF was additionally pumped from the wide side by $80 \mathrm{~W}$ diode. The pumping scheme was realized through dichroic filter, and the light was coupled to active fiber via focusing lens. The maximum output power was $55 \mathrm{~W}$, what corresponded to the efficiency of $61 \%$ and $34.4 \mathrm{~dB}$ gain. The Figure $6 \mathrm{~b}$ illustrates the corresponding spectra measured at different output power levels. At the maximum output power of $55 \mathrm{~W}$, we recorded a slight broadening of the spectrum till $6 \mathrm{~nm}$ at $3 \mathrm{~dB}$ level.

As visible from Figure 6a, the sT-DCF length of $3.1 \mathrm{~m}$ had higher efficiency, about 69\%. At the same time, $3.4 \mathrm{~m}$ long fiber had almost the same efficiency as $2.75 \mathrm{~m}$ long fiber. This could be explained by the fact that sT-DCF was very sensitive to the cleave angle. For example, with flat cleaves perpendicular to the length of the fiber, the output power 
dropped by almost 2 times, and back reflections deteriorated the performance. Because of strong internal stresses and atypical geometry, it was difficult to produce an angle cleave of the optimal value.

\section{CONCLUSION}

In conclusion, we have demonstrated at the first time, to the best of our knowledge, a spun active tapered double clad fiber. Experimentally, we investigated the influenced of the torsional mechanical stresses on the output beam shape and quality, and determined the optimum for core/cladding and pitch parameters equaled to $35 / 280 \mu \mathrm{m}$ and $6 \mu \mathrm{mm}$, correspondingly. Since a larger modal field diameter is always desirable, in the future we are planning to investigate sTDCF with a larger MFD and a pitch of $5 \mathrm{~mm}$ or less. The question of what pitch is optimal for large core requires further experimental study. Having a core diameter of $35 \mu \mathrm{m}$, sT-DCF operated in a strictly single mode regime with excellent beam quality $\left(\mathrm{M}^{2}=1.18 / 1.10\right)$ and demonstrated MFD of $26 \mu \mathrm{m}$. The sT-DCF revealed good polarization-maintaining properties preserving the linear polarization of the input beam with minor degradation at higher output power. A new tapered fiber was utilized for high power amplification in all-fiber picosecond MOPA system delivered $4 \mu \mathrm{J}, 50 \mathrm{ps}$ pulses with $55 \mathrm{~W}$ average power (34.4 dB gain).

\section{ACKNOWLEDGMENT}

This work was supported by Academy of Finland Postdoctoral research project (285170) and PULSE project, grant agreement number 824996, funded by the European Commission Horizon 2020 Program.

\section{REFERENCES}

[1] Filippov, V., Chamorovskii, Y., Kerttula, J., Golant, K., Pessa, M., and Okhotnikov, O. G., "Double clad tapered fiber for high power applications," Opt. Express 16, 1929-1944 (Feb 2008).

[2] Filippov, V., Chamorovskii, Y. K., Golant, K. M., Vorotynskii, A., and Okhotnikov, O. G., "Optical amplifiers and lasers based on tapered fiber geometry for power and energy scaling with low signal distortion," Proc. SPIE 9728, Fiber Lasers XIII: Technology, Systems, and Applications, (Invited) 97280V (2016).

[3] Filippov, V., Kerttula, J., Chamorovskii, Y., Golant, K., and Okhotnikov, O. G., "Highly efficient 750 W tapered double-clad ytterbium fiber laser," Opt. Express 18, 12499-12512 (Jun 2010).

[4] Shi, C., Zhang, H., Wang, X., Zhou, P., and Xu, X., "kW-class high power fiber laser enabled by active long tapered fiber," High Power Laser Science and Engineering 6, e16 (2018).

[5] Trikshev, A. I., Kurkov, A. S., Tsvetkov, V. B., Filatova, S. A., Kertulla, J., Filippov, V., Chamorovskiy, Y. K., and Okhotnikov, O. G., "A $160 \mathrm{~W}$ single-frequency laser based on an active tapered double-clad fiber amplifier," Laser Physics Letters 10, 065101 (Apr 2013).

[6] Filippov, V., Vorotynskii, A., Noronen, T., Gumenyuk, R., Chamorovskii, Y., and Golant, K., "Picosecond mopa with ytterbium doped tapered double clad fiber," Fiber Lasers XIV: Technology and Systems, edited by Craig A. Robin, Ingmar Hartl, Proc. SPIE vol. 10083, pp. 100831H-1 100831H-6 (2017).

[7] Fedotov, A., Noronen, T., Gumenyuk, R., Ustimchik, V., Chamorovskii, Y., Golant, K., Odnoblyudov, M., Rissanen, J., Niemi, T., and Filippov, V., "Ultra-large core birefringent yb-doped tapered double clad fiber for high power amplifiers," Opt. Express 26, 6581-6592 (Mar 2018).

[8] Pierre, C., Guiraud, G., Vin ,cont, C., Traynor, N., Santarelli, G., and Boullet, J., "120w single frequency laser based on short active double clad tapered fiber," in 2017 European Conference on Lasers and Electro-Optics and European Quantum Electronics Conference, CJ 93, Optical Society of America (2017).

[9] Ustimchik, V. E., Rissanen, J., Popov, S. M., Chamorovskii, Y. K., and Nikitov, S. A., "Anisotropic tapered polarization-maintaining large mode area optical fibers," Opt. Express 25, 10693-10703 (May 2017).

[10] Rashleigh, S., "Origins and control of polarization effects in single-mode fibers," Journal of Lightwave Technology 1, 312-331 (June 1983).

[11] Wang, Y., Xu, C.-Q., and Izraelian, V., "Characterization of spun fibers with millimeter spin periods," Opt. Express 13, 3841-3851 (May 2005). 
[12] Chamorovskiy, Y., Starostin, N., Ryabko, M., Sazonov, A., Morshnev, S., Gubin, V., Vorobev, I., and Nikitov, S., "Miniature microstructured fiber coil with high magneto-optical sensitivity," Optics Communications 282(23), 4618 - 4621 (2009). 